\title{
Inhibitory Activities of Bovine Macromolecular Whey Proteins on Rotavirus Infections In Vitro and In Vivo
}

\author{
A. Bojsen, ${ }^{*}$ J. Buesa,† R. Montava,† A. S. Kvistgaard,‡ M. B. Kongsbak, ${ }^{\star}$ \\ T. E. Petersen, ${ }^{\star}$ C. W. Heegaard, ${ }^{\star}$ and J. T. Rasmussen ${ }^{\star 1}$ \\ *Protein Chemistry Laboratory, University of Aarhus, 8000 Aarhus C, Denmark \\ †Department of Microbiology, School of Medicine, University of Valencia and Hospital Clínico Universitario, Valencia, Spain \\ $\ddagger$ Arla Foods, Aarhus, 8260 Viby J, Denmark
}

\section{ABSTRACT}

Rotavirus is a major cause of infantile viral gastroenteritis and can lead to severe and sometimes lethal dehydration. Previous studies have shown that breastfed children are better protected against symptomatic infections, and that the milk fat globule protein lactadherin might be at least partly responsible for this effect. In vitro studies have shown that human lactadherin, in contrast to the bovine ortholog, could inhibit rotavirus infectivity, and that bovine MUC1 and a commercially available bovine macromolecular whey protein (MMWP) fraction proved to be effective. The present work describes the versatility of MMWP against the infection of 2 human intestinal cell lines (Caco-2 and FHs 74 Int) by 4 different rotavirus strains (Wa, RRV, $\mathrm{YM}, \mathrm{RF}$ ). Isolation of a protein fraction (CM3Q3) from MMWP that effectively inhibits rotavirus infectivity in vitro is documented. Purification was achieved by monitoring the rotaviral inhibitory activity in fractions obtained from 2 consecutive steps of ion-exchange chromatography. The major component of CM3Q3 was shown to be bovine IgG, and the attenuating capacity of this fraction is most properly linked to this component. The capacity of MMWP, MUC1, lactadherin, and the CM3Q3 fraction to inhibit the infectivity of the murine $\mathrm{EMcN}$ rotavirus strain was analyzed in adult BALB/c mice by using 2 different amounts of virus (10 and 100 times more than $50 \%$ the viral shedding doses). Only CM3Q3 was able to significantly affect the shedding of rotavirus in the stools of experimentally infected mice when the high viral dose was given. Detection of rotavirus-specific serum antibodies showed that the high dose infected all groups of mice. Experiments with the low dose of virus implied that all the tested milk proteins could affect the viral shedding in stools; in addition, use of MUC1, MMWP, and CM3Q3 prevented the appearance of serum viral antibodies. The advan-

Received June 26, 2006.

Accepted August 16, 2006.

${ }^{1}$ Corresponding author: jatr@mb.au.dk tages of using bovine immunoglobulins to induce passive immunity against rotavirus have been substantially investigated, although studies have mainly focused on the use of derivatives from immunized cows, especially colostrum. This report associates considerable activity against rotavirus infectivity with an ordinary whey product, suggesting that there might be alternatives to colostral-derived products.

Key words: rotavirus, antibodies, whey protein

\section{INTRODUCTION}

Rotaviruses are the most common agents of severe gastroenteritis in infants and young children, causing approximately 600,000 deaths among children under 5 yr of age in developing countries and 1.4 billion episodes of diarrhea worldwide annually (Parashar et al., 2003, 2006). Vaccines are being developed to reduce the huge impact of this disease (Glass and Parashar, 2006). Rotavirus infects the upper and mid part of the villi in mature enterocytes in the small intestine (for reviews see Jiang et al., 2002; Kosek et al., 2003). A picture of the mechanism involved in the attachment of rotavirus and infection is beginning to emerge (for a review see Arias et al., 2002).

Cell culture studies have previously revealed the presence of components in human milk with the ability to inhibit rotavirus replication (Yolken et al., 1992). A mucin complex containing the milk fat globule membrane proteins MUC1, butyrophilin, and lactadherin have shown to be especially interesting. Results from this work caused Yolken and coworkers to suggest that lactadherin could be a major inhibitor of rotavirus infections. This was supported by a successive cohort of clinical studies, performed by some of the same authors, that evaluated the correlation between lactadherin in breast milk and symptomatic rotavirus infections. The results obtained implied an increased risk of catching a symptomatic rotavirus infection when the lactadherin concentration was low (Newburg et al., 1998).

A recent investigation that analyzed the in vitro inhibitory effects of human and bovine milk constituents 
on rotavirus infections clearly demonstrated that human lactadherin in fact holds rotavirus inhibitory activity (Kvistgaard et al., 2004). On the contrary, no antiviral activity could be attributed to bovine lactadherin. Still, the presence of bovine milk-derived inhibitory components could be seen, namely, MUC1, together with the more crude fractions of milk fat globule membrane and a macromolecular whey protein (MMWP) fractions (Kvistgaard et al., 2004). Although lactoferrin was found to be present in MMWP, experiments conducted in the same work failed to show any inhibitory activity of pure bovine lactoferrin. This is in conflict with results published by others showing that bovine lactoferrin inhibits infection by the simian neuraminidase-sensitive rotavirus strain SA11 in HT-29 cells (Superti et al., 1997, 2001). Why these studies reached such different conclusions is not apparent.

Other studies have also examined the existence of rotavirus inhibitory components in bovine milk in vitro. Kanamaru et al. (1999) showed that a high molecular weight fraction from bovine whey protein possessed an antiviral effect. The components MUC1, lactadherin, and an unidentified $80-\mathrm{kDa}$ protein were among the prominent constituents in this fraction, and the authors suggested that the inhibitory activity in whey was associated with components with molecular weights below $80 \mathrm{kDa}$. In the same study, a human milk fraction prepared in a roughly similar manner, except that an affinity column was included to remove IgG, also showed antiviral activity. This fraction primarily contained MUC1. Finally, Wolber et al. (2005) recently reported that a bovine whey protein concentrate demonstrated prophylactic properties when fed to suckling mice.

The aim of the present study was to isolate and identify components responsible for the inhibitory activity of MMWP toward rotavirus infectivity seen in vitro and to test their effectiveness in vivo.

\section{MATERIALS AND METHODS}

\section{Materials}

All chemicals (analytical grade) were supplied by Sigma-Aldrich Corp. (St. Louis, MO) or Merck \& Co., Inc. (Whitehouse Station, NJ), aside from the specified exceptions. All tissue culture media and supplements were purchased from Gibco Invitrogen Corp. (Paisley, UK) unless otherwise specified. Culture plates were from BD Falcon (BD Biosciences Discovery Labware, Boston, MA). Ion-exchange resins (CM-Sepharose FF and Q-Sepharose FF) were purchased from GE Healthcare BioSciences AB (Uppsala, Sweden). Bovine macromolecular whey proteins were a spray-dried retentate obtained by microfiltration $(0.1$ to $0.2 \mu \mathrm{m})$ of whey from commercial yellow cheese production. The MMWP ma- terial was produced and kindly donated by Arla Foods Ingredients (Nr. Vium, Denmark).

\section{Protein Purification}

The MMWP were solubilized in $0.05 M$ ammonium acetate ( $\mathrm{pH}$ 5.0) and $8 M$ urea, and applied to a CMSepharose FF column $(5 \times 13 \mathrm{~cm})$, with flow at $30 \mathrm{~mL} /$ $\mathrm{h}$ at room temperature. Proteins were eluted with an ammonium acetate gradient $(0.050$ to $1 M$ ) and monitored at $280 \mathrm{~nm}$. Fractions $(10 \mathrm{~mL})$ were pooled as depicted, dialyzed against water, and freeze-dried. Further separation was achieved using a Q-Sepharose FF column $(2.5 \times 18 \mathrm{~cm})$, with flow at $120 \mathrm{~mL} / \mathrm{h}$, and a gradient going from 0.02 to $1 M \mathrm{NH}_{4} \mathrm{HCO}_{3}(\mathrm{pH} 7.8$ ). Fractions $(9 \mathrm{~mL})$ were pooled by inspection of the elution profile $(280 \mathrm{~nm})$, dialyzed (cutoff 12 to $14 \mathrm{kDa}$ ) against water, and finally freeze-dried.

Bovine lactadherin and MUC1 were purified as described previously (Hvarregaard et al., 1996; Pallesen et al., 2001). Proteins were visualized by SDS-PAGE and staining with Coomassie Brilliant Blue R-250 using standard procedures. Quantification was done either by AA analysis (ortho-phthalaldehyde-based) or by the Lowry method as modified by Schacterle and Pollack (1973). Western blots were probed with rabbit antibovine IgG antibodies (Bethyl Inc., Montgomery, TX) and performed as previously described (Benfeldt et al., 1995).

\section{Rotavirus Propagation and Rotavirus Infection Assays}

The embryonic monkey kidney cell line MA104 was used to propagate the different rotavirus strains used in this study in the presence of $1 \mu \mathrm{g} / \mathrm{mL}$ of trypsin: strains Wa (human), RF (bovine), YM (porcine), and RRV (simian). Viral stocks of the EMcN strain of murine rotavirus (kindly provided by Richard Ward, Children's Hospital Medical Center, Cincinnati, $\mathrm{OH}$ ) were prepared by orally infecting 8-wk-old BALB/c mice. Stools were collected, pooled, homogenized in $0.05 \mathrm{M}$ Tris- $\mathrm{HCl}(\mathrm{pH} 7.5), 0.15 \mathrm{M} \mathrm{NaCl}$, and $0.01 \mathrm{M} \mathrm{CaCl}_{2}$, and then aliquoted and stored at $-80^{\circ} \mathrm{C}$ until use. The $50 \%$ viral shedding dose $\left(\mathbf{S D}_{\mathbf{5 0}}\right)$ was determined by oral inoculation of 8-wk-old mice with serial 10 -fold dilutions of the viral stock and then analyzing the viral antigen shed in stools by a sensitive ELISA as previously described (García-Díaz et al., 2004), analyzed according to the method of Reed and Muench (1938).

The in vitro infection assays were performed using human enterocyte-like Caco-2 cells or FHs 74 Int (DSMZ, Braunschweig, Germany). Both Caco-2 and FHs 74 Int cells were cultured in Dulbecco's minimal 
essential medium with Glutamax. Virus propagation and infection assays were performed as previously described (Kvistgaard et al., 2004).

\section{Rotavirus Infection Assay in the Mouse Model}

The in vivo inhibitory effect of bovine whey proteins on rotavirus infectivity was evaluated using the adult mouse model of rotavirus infection, in which the determinant for the severity of infection following challenge with a murine rotavirus was the amount of rotavirus antigen shed in stools (Ward et al., 1990). The adult mouse is a model of infection, not of disease, because diarrhea is age-restricted to animals under $2 \mathrm{wk}$ of age (Burns et al., 1995; Gil et al., 2000).

An inbred BALB/c strain of mice (Charles River Laboratories, Santa Perpetua de Mogoda, Barcelona, Spain) and the EMcN strain of murine rotavirus (McNeal et al., 2004) were used in this study. Mice were previously confirmed by ELISA to be negative for antirotavirus antibodies. They were housed in plastic microisolator cages before and after viral challenge. All animal procedures were conducted in accordance with the regulations established by the European Community Council on the protection of animals with experimental and scientific applications (European Union, 1986).

The capacity of the different milk protein fractions to inhibit rotavirus infectivity were tested by using the $\mathrm{EMcN}$ strain, which previously was found to be consistently shed in great quantities in adult $\mathrm{BALB} / \mathrm{c}$ mice. Dilutions $(0.1 \mathrm{~mL})$ of each purified protein (MMWP, MUC1, lactadherin, and CM3Q3) in $4.3 \mathrm{mM} \mathrm{Na}{ }_{2} \mathrm{H}-$ $\mathrm{PO}_{4} \cdot 7 \mathrm{H}_{2} \mathrm{O}, 1.4 \mathrm{mM} \mathrm{KH}_{2} \mathrm{PO}_{4}(\mathrm{pH} 7.2), 137 \mathrm{mM} \mathrm{NaCl}$, $2.7 \mathrm{~m} M \mathrm{KCl}(\mathrm{PBS})$ at a concentration at $0.5 \mathrm{mg} / \mathrm{mL}$ were mixed with an equal volume of a $\mathrm{EMcN}$ suspension $\left(100 \mathrm{SD}_{50}\right)$ and incubated at $37^{\circ} \mathrm{C}$ for $30 \mathrm{~min}$. Groups of 10 female mice ( 8 to $10 \mathrm{wk}$ of age) were given the protein-virus mixture by oral gavage with a ball-tipped needle. At $12 \mathrm{~h}$ postchallenge, the mice were given another dose (same amount) of the actual protein fraction by oral gavage to extend the in vivo interaction between the protein and the virus. Stools were collected daily over $13 \mathrm{~d}$ following the challenge to quantify by ELISA the amount of rotavirus antigen shed in the feces.

Quantification of rotavirus shedding was determined individually in the groups of $\mathrm{BALB} / \mathrm{c}$ mice given the viral inoculum previously incubated with the different purified whey proteins and compared with virus shed by rotavirus-infected control mice and by mice challenged with the same viral inoculum preincubated with BSA.

Rotavirus-specific antibodies in mouse sera were analyzed by ELISA, using this as a marker for viral infection. Blood samples were taken from the tail vein of the mice 3 wk after oral administration of the protein-

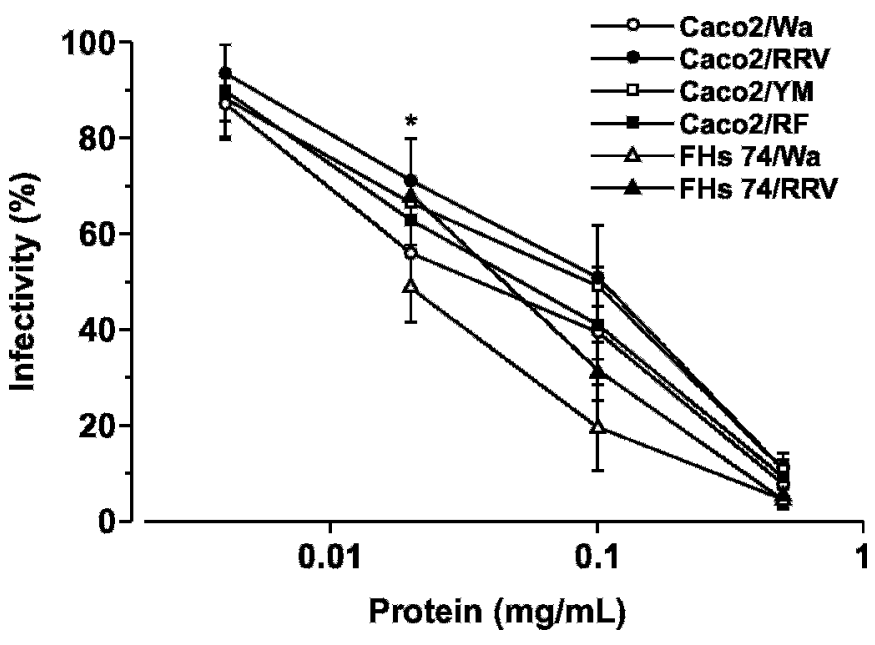

Figure 1. Dose-response effects of macromolecular whey protein (MMWP) on WA, RRV, YM, and RF rotavirus infectivity of Caco-2 and FHs 74 Int cells in relation to controls (no protein). Logarithmic presentation: Wa infection of Caco-2 cells (open circles); RRV infection of Caco-2 cells (solid circles); YM infection of Caco-2 cells (open squares); RF infection of Caco-2 cells (solid squares); Wa infection of FHs 74 Int cells (open triangles); RRV infection of FHs 74 Int cells (solid triangles). Results are shown as mean \pm standard deviation of at least 2 experiments performed in triplicate. The first points with statistically significant effects $(P<0.05)$ are indicated with an asterisk (*).

virus mixture. Measurement of IgG antirotavirus antibodies in serum samples diluted 1:10, 1:100, and 1:500 were determined by ELISA.

\section{Statistical Analysis}

Effects of protein samples on rotavirus infectivity in relation to controls (no protein) were tested for statistical significance by using Student's $t$-test. Differences in the shedding of rotavirus antigen in feces and in the levels of rotavirus-specific serum antibodies between groups of mice were compared by the Mann-Whitney $U$-test. A probability of $<0.05$ was considered statistically significant.

\section{RESULTS}

\section{Efficient and Versatile Inhibitory Activity of Bovine MMWP Against Rotavirus In Vitro}

The ability of MMWP to inhibit the infectivity of 4 different rotavirus strains was tested by in vitro assays using 2 different intestinally derived human cell lines, Caco-2 and FHs 74 Int (Figure 1). Upon addition of increasing amounts of MMWP, the MMWP demonstrated an equal ability to reduce the number of infections produced by all 4 tested rotavirus strains, regardless of the type of cells used in the assay. In all combina- 
tions of cells and viruses, a largely logarithmic linearity could be demonstrated between the added amount of protein and the inhibitory efficiency. Statistically significant effects were obtained at $0.02 \mathrm{mg} / \mathrm{mL}$ in all cases examined. To our knowledge, this is the first time that it has been shown that the FHs 74 Int cell line, which is derived from the small intestine, can be used in an in vitro rotavirus infection assay. However, it should be noted that the cultured FHs 74 Int cells must be treated extremely thoroughly to avoid detachment during the washing and immunostaining steps. In addition, control experiments with BSA (up to $8 \mathrm{mg} / \mathrm{mL}$ ) showed that the observed effects could not be attributed to nonspecific binding (results not shown), a result that was in accordance with previously performed experiments (Guerrero et al., 2000).

The stability of the observed rotaviral-inhibitory capacity of MMWP was tested by investigating the resistance toward heat and protease treatment. After incubating MMWP $(10 \mathrm{mg} / \mathrm{mL})$ in a water bath $(10 \mathrm{~min}$ at $85^{\circ} \mathrm{C}$ ), the infectivity rate decreased to about $62 \%$, whereas incubation with pepsin (1\% wt, $1 \mathrm{~h}, \mathrm{pH} 2.0$ ) resulted in an infectivity rate of $64 \%$ when using 0.5 $\mathrm{mg}$ of protein/mL in a Wa/Caco-2 assay (results not shown). In both cases, this was a dramatic shift from the usual $\sim 5 \%$ infectivity observed with an untreated MMWP sample.

\section{Isolation of an Active Fraction}

The MMWP fraction contained large amounts of lipids (17.2\% according to the producer) and membraneassociated proteins. Therefore, it was necessary to solubilize the MMWP components by using detergent or chaotropic reagents prior to chromatographic separation. Accordingly, the constituents of MMWP were then initially separated by cation-exchange chromatography (CM-Sepharose) in an ammonium acetate buffer $(\mathrm{pH}$ 5.0) containing $8 M$ urea (Figure 2A). The obtained fractions were divided into 5 pools, and the constituting proteins were visualized by SDS-PAGE (Figure 2A, insert). After dialysis and lyophilization, the pooled fractions were assessed for the ability to inhibit rotavirus infection in vitro (Figure 2B). Fraction 3 (CM3) clearly had the most pronounced inhibitory effect (infectivity of only approximately $23 \%$ by $0.1 \mathrm{mg}$ of protein $/ \mathrm{mL}$ ), even though the obtained data demonstrated large variations.

To achieve a higher degree of purification, the CM3 fraction was loaded on an anion-exchange column (QSepharose) at $\mathrm{pH} 7.8$, again after the gradient elution fractions were pooled, dialyzed, and freeze-dried. The proteins present were analyzed by SDS-PAGE and tested in a rotavirus infectivity assay (Figure 3 ).
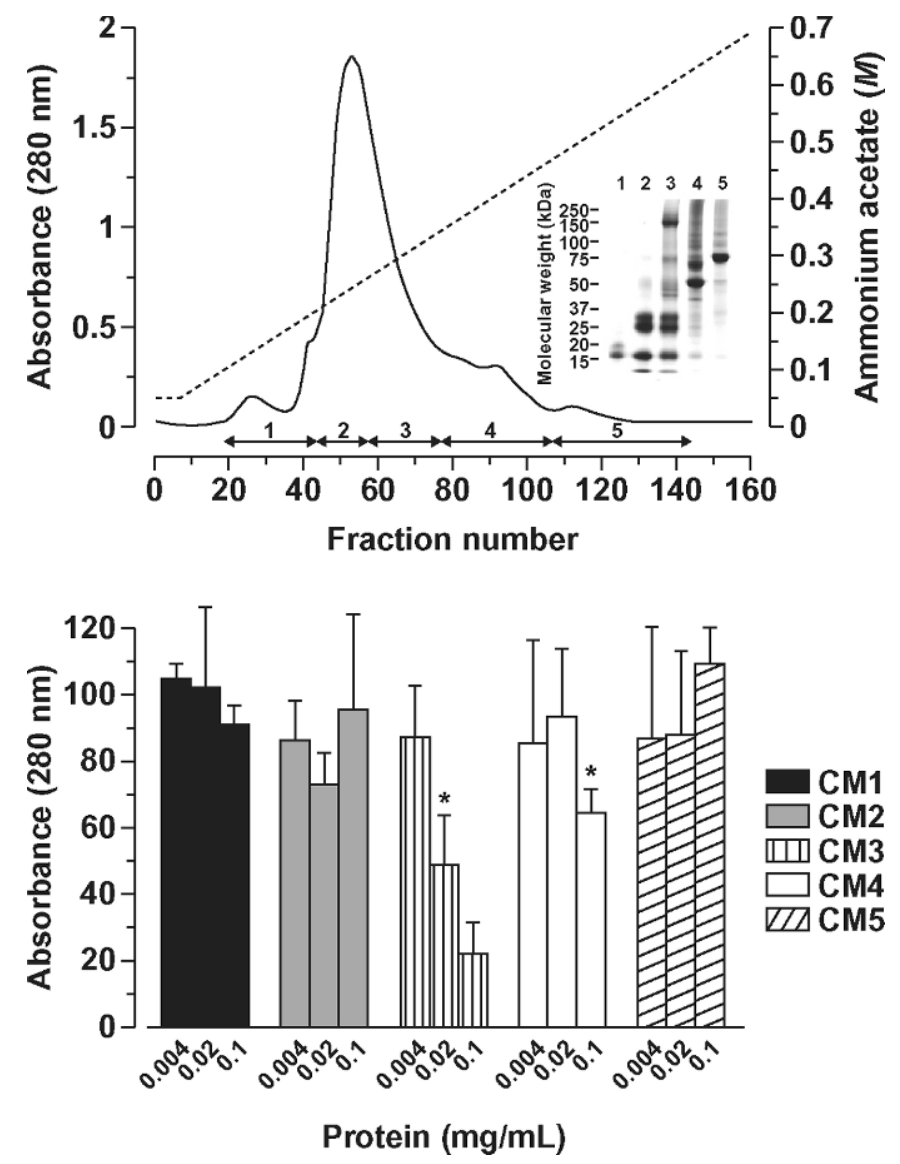

Figure 2. Separation of proteins in macromolecular whey protein (MMWP) by cation-exchange chromatography. (A) Purification was performed in $50 \mathrm{~m} M$ ammonium acetate ( $\mathrm{pH}$ 5.0) with $8 M$ urea on a 255-mL CM-Sepharose FF column. Proteins were eluted with a gradient of 0.05 to $1 \mathrm{M}$ ammonium acetate (dotted line) and monitored at $280 \mathrm{~nm}$ (solid line). After separation, the indicated fractions were selected for 5 pools, named CM1 to CM5. Insert: SDS-PAGE analysis of the obtained protein pools. Gels (18\% acylamide with a Tris-glycine buffer system) were stained with Coomassie Brilliant Blue R-250. Lanes 1 to 5: CM1 to CM5, respectively. Positions of molecular mass standards are indicated. (B) Analyses of the effects on the infectivity of the Wa rotavirus onto Caco-2 cells of collected CM pools given as the mean \pm standard deviation of at least 2 experiments performed in triplicate. The first points with a statistically significant effect $(P$ $<0.05)$ are indicated with an asterisk $(*)$.

The majority of the inhibitory effect was located in the third fraction (Q3) and it faded away in fractions Q4 and Q5. The CM3Q3 fraction inhibited Wa rotavirus infectivity very efficiently (only approximately $2 \%$ infection at $0.1 \mathrm{mg}$ of protein $/ \mathrm{mL}$ ), which is a $20 \times$ reduction in comparison with the same amount of the MMWP fraction (about $40 \%$ infectivity).

\section{Characterization of Protein Components in the Active Fraction}

By analysis with SDS-PAGE, the main component in CM3Q3 was shown to have a molecular mass close to 

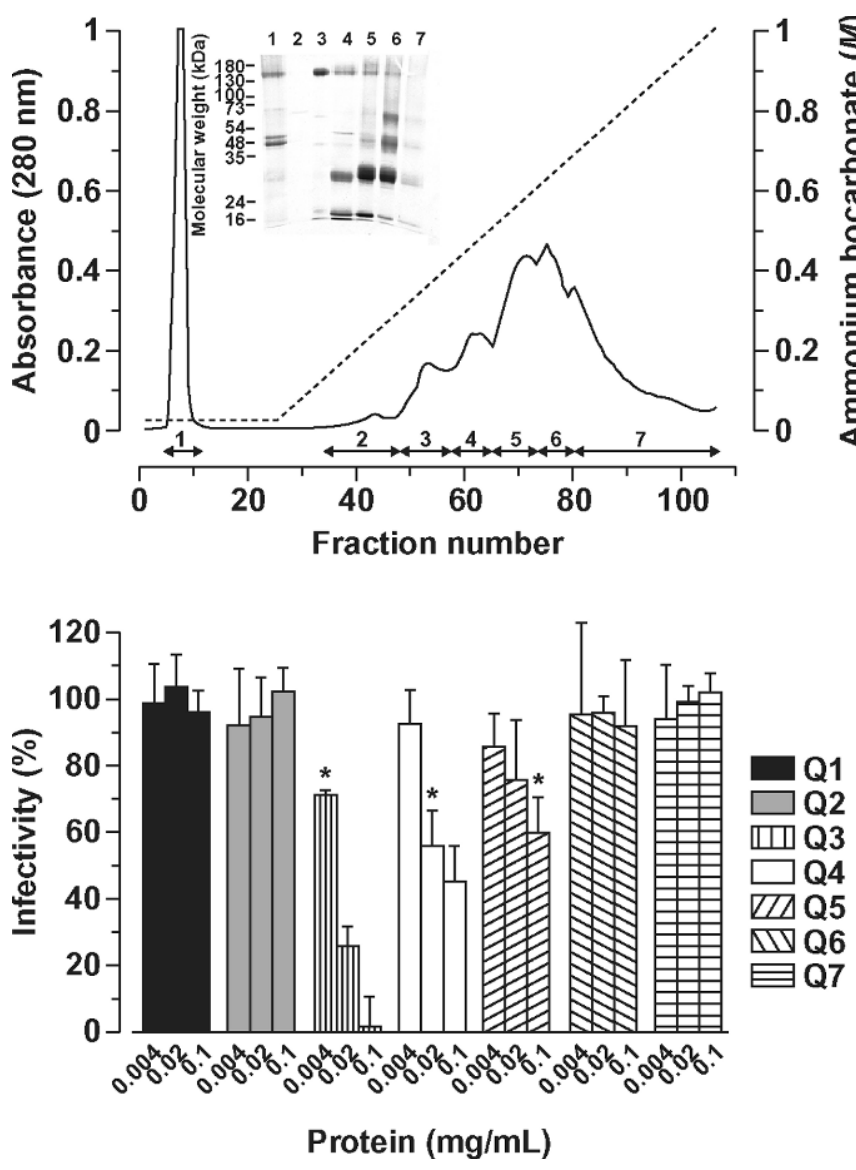

Figure 3. Separation of proteins in CM-Sepharose column fraction 3 (CM3) by anion-exchange chromatography. (A) Purification was performed on an 88-mL Q-Sepharose FF column and the proteins were eluted with a gradient (dotted line) of ammonium bicarbonate $(0.02$ to $1 \mathrm{M})$. Absorbance at $280 \mathrm{~nm}$ is shown (solid line). After separation, the indicated fractions were selected for 7 pools, named CM3Q1 to CM3Q7. Insert: SDS-PAGE (18\%) analysis of the obtained CM3Q pools (Coomassie stained). Lanes 1 to 7: CM3Q1 to CM3Q7, respectively. Mobility of the molecular mass standards is indicated. (B) Ability of the collected CM3Q pools to affect Wa infectivity (Caco2 ), given as mean \pm standard deviation of at least 2 experiments performed in triplicate. The first points with statistically significant effects $(P<0.05)$ are indicated with an asterisk (*).

$145 \mathrm{kDa}$ under nonreducing conditions, whereas reduction led to the appearance of 2 bands at approximately 50 and $24 \mathrm{kDa}$ (Figure 4). This behavior strongly suggested IgG as the major constituent, which was also demonstrated by Western blotting probed with rabbit antibovine IgG antibodies (Figure 4). Finally, analysis by matrix-assisted laser desorption-ionization time-offlight mass spectrometry confirmed the identity of the $145-\mathrm{kDa}$ band as bovine IgG (results not shown). During the separation of CM3Q3, the antiviral activity was monitored using the human-derived rotavirus strain Wa. However, as seen for the source material (Figure 1), CM3Q3 was shown to be equally effective in preventing

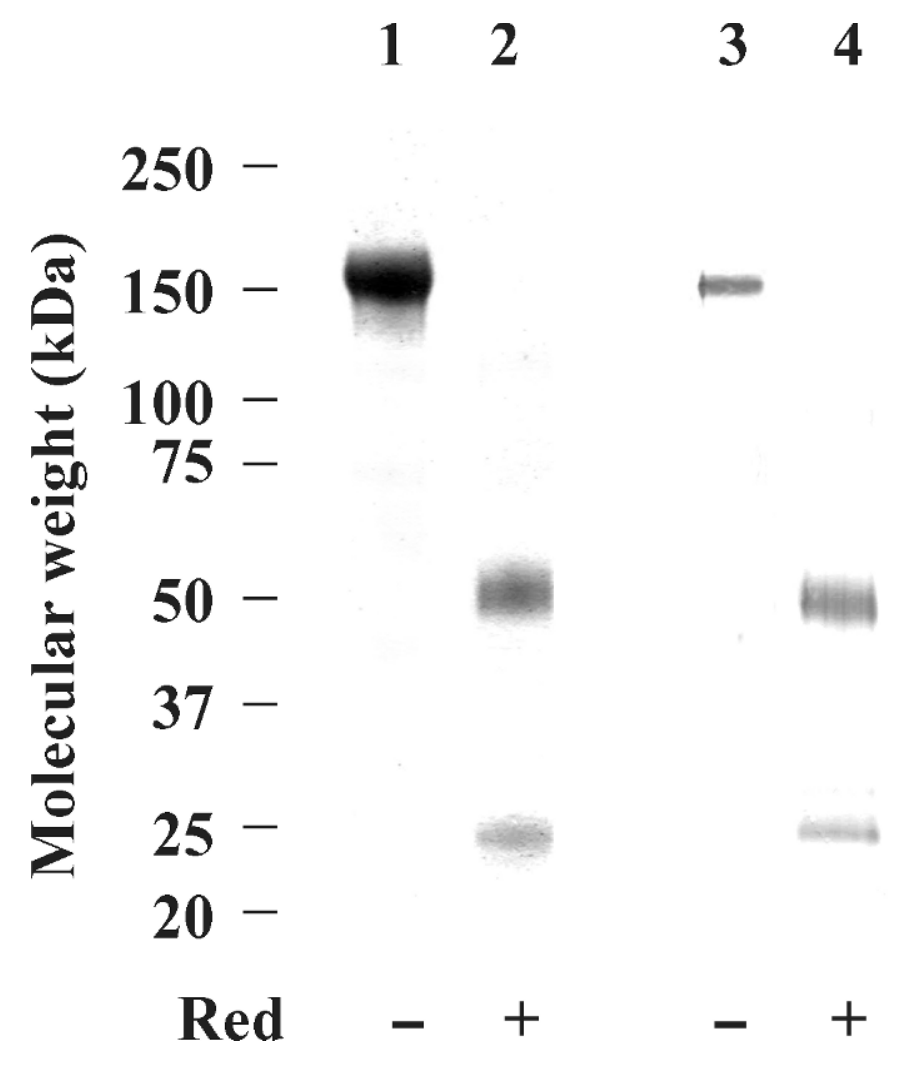

Figure 4. Effect of reducing agents on the isolated CM3Q3 fraction. Reduction was performed by adding 1,4-dithioerythritol to a final concentration at $18 \mathrm{mM}$. Lanes 1 and 2: SDS-PAGE analysis of CM3Q3 (18\%, Coomassie stained). Lanes 3 and 4: Western blot analysis of CM3Q3 probed with antibovine IgG antibodies. Reductive status of the sample buffer is indicated (+/-).

cellular infection with the RF, YM, and RRV strains as well (results not shown).

In Vivo Evaluation of the Inhibitory Effects of Purified Whey Proteins on Rotavirus Infectivity. Figure 5A shows the amounts of rotavirus antigen shed in stools by BALB/c mice given a viral challenge of 100 $\mathrm{SD}_{50}$ of the EMcN strain previously incubated with the different purified whey proteins (MMWP, MUC1, lactadherin, and the CM3Q3 fraction). For comparison, antigens shed by control mice inoculated with $100 \mathrm{SD}_{50}$ of EMcN and by mice given the same inoculum previously incubated with BSA were included. Viral shedding was detected in the stools $24 \mathrm{~h}$ postchallenge and for $7 \mathrm{~d}$ in all the experimental and control groups, except in those mice given $100 \mathrm{SD}_{50}$ of $\mathrm{EMcN}$ preincubated with the CM3Q3 fraction. In this group of mice, rotavirus shedding was detected on the sixth day postchallenge and reached a maximum peak at the ninth day, also lasting $7 \mathrm{~d}$. Significant differences $(P<0.05$ in the Mann-Whitney $U$-test) were found when comparing the absorbance values among mice given the virus mixed with the CM3Q3 fraction and the control groups. Serum 

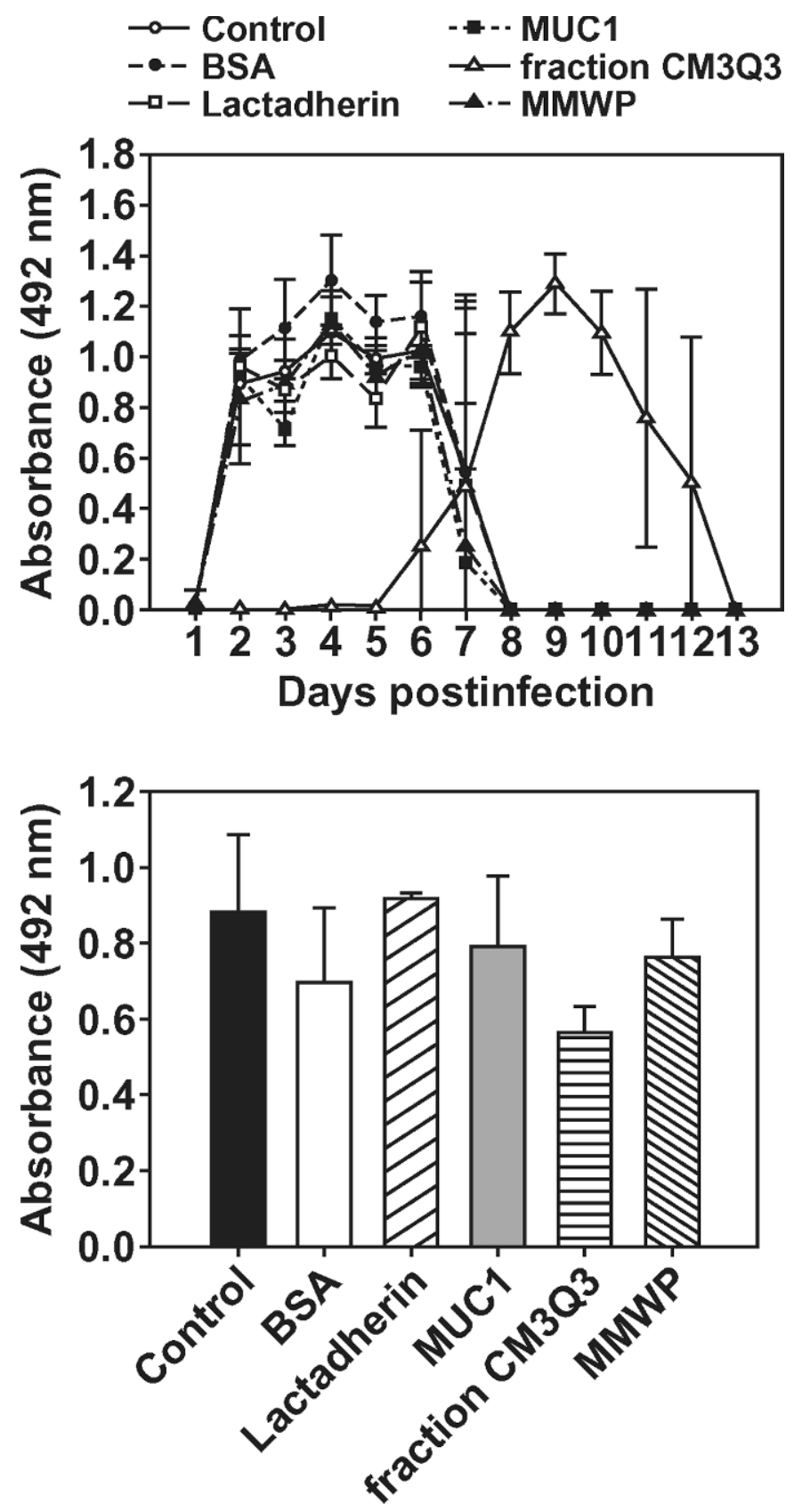

Figure 5. Mice (BALB/c) were challenged orally with $10050 \%$ shedding doses of the murine EMcN rotavirus. (A) Rotavirus antigen shedding in stools. Results are given as the mean value \pm standard deviation of triplicate absorbance values at $492 \mathrm{~nm}$, which reflect the viral shedding for each mouse group ( $\mathrm{n}=10$ mice per group). Groups of mice were given the virus alone (control mice, open circles), or the virus preincubated with either BSA (solid circles), lactadherin (open squares), MUC1 (solid squares), the CM3Q3 fraction (open triangles), or macromolecular whey protein (MMWP; solid triangles). Serum samples were collected $3 \mathrm{wk}$ after virus inoculation. (B) Rotavirusspecific serum IgG antibodies determined by ELISA. Values for absorbance at $492 \mathrm{~nm}$ correspond to the 1:100 serum dilutions. antirotavirus IgG antibodies were found in all the groups of mice as well as in the control groups (Figure $5 \mathrm{~B})$, confirming that all the animals had been infected. No significant differences were found in the absorbance values among serum samples from mice given the rotavirus incubated with lactadherin, MUC1, the CM3Q3 fraction, and MMWP and the control groups (virus alone and incubated with BSA; $P<0.05$ ).

A markedly different pattern emerged when the content of $\mathrm{EMcN}$ was lowered to $10 \mathrm{SD}_{50}$ in the viral inoculum while the amount of protein fractions remained unchanged. All the assayed milk-derived protein fractions (MMWP, MUC1, lactadherin, and the CM3Q3 fraction) were shown to suppress the shedding of rotavirus antigen in all the inoculated mice. Only the control groups of mice (those given untreated viral inoculum and virus incubated with BSA) shed rotavirus antigen from d 4 until d 9 postchallenge (Figure 6A). Antirotavirus IgG serum antibody was demonstrated only in those animals challenged with virus incubated with lactadherin and in the group of control mice (Figure 6B). Differences in the absorbance values among the serum samples from mice given rotavirus incubated with MUC1, the CM3Q3 fraction, and MMWP and the control group were statistically significant $(P<0.05)$.

\section{DISCUSSION}

The present work demonstrates that it is possible to isolate a protein fraction (CM3Q3) from a commercial whey product (MMWP) that effectively inhibits rotavirus infectivity in vitro. Purification was achieved by 2 consecutive ion-exchange chromatography steps, namely, cation-exchange (CM-Sepharose) at pH 5.0 in the presence of $8 M$ urea and anion-exchange (Q-Sepharose) at $\mathrm{pH}$ 7.8. In vivo studies conducted in mice linked a significant protective effect against rotavirus infection to MMWP, but especially to the CM3Q3 fraction. Bovine IgG was shown to be the main constituent of CM3Q3.

To facilitate the purification process, it was necessary to include urea during the first ion-exchange step. However, the following step could be performed without any denaturing substance, implying that a majority of the proteins in the CM3 fraction were soluble when the phospholipids had been removed.

Characterization of the CM3Q3 fraction revealed that IgG was the major constituent. It was further established that the minor constituents were not responsible for the antiviral effect. First, introduction of an additional purification step of CM3Q3 by Superose 12 gel-filtration showed that activity against rotavirus could be ascribed only to bovine IgG (results not shown). Second, analysis by matrix-assisted laser desorption- 

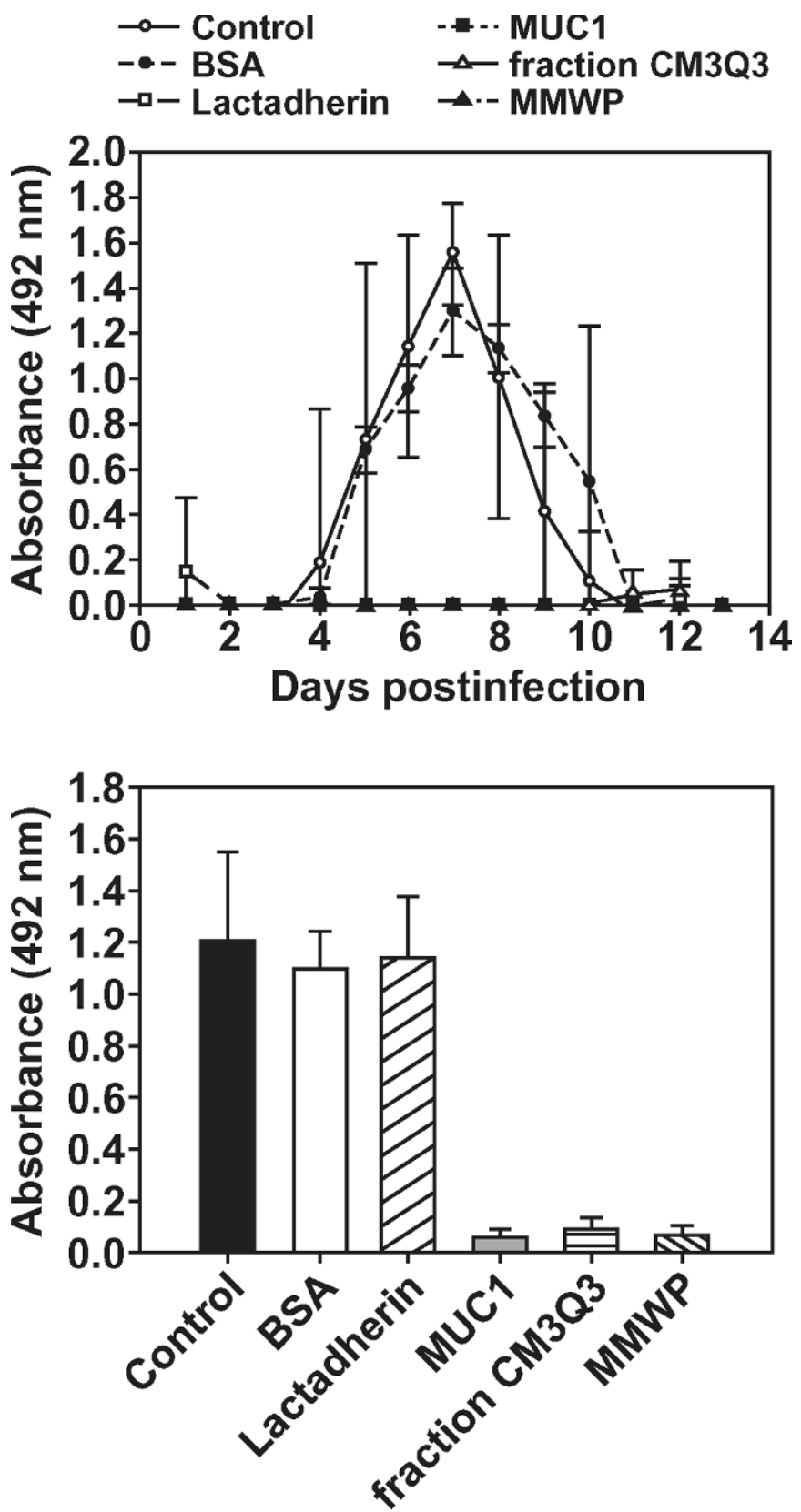

Figure 6. Effect on BALB/c mice ( $\mathrm{n}=10$ per group) of oral administration of a reduced amount of the murine EMcN rotavirus (10 50\% shedding doses). (A) Rotavirus antigen shedding in stools of BALB/ c mice (mean value \pm standard deviation). Groups of mice were given the virus alone (control mice, open circles), or the virus preincubated with either BSA (solid circles), lactadherin (open squares), MUC1 (solid squares), the CM3Q3 fraction (open triangles), or macromolecular whey protein (MMWP; solid triangles). Serum samples were collected $3 \mathrm{wk}$ after virus inoculation. (B) Test for rotavirus-specific serum IgG antibodies in the challenged mice.

ionization time-of-flight mass spectrometry showed that the main contaminants were poly-IgG receptor, lactadherin, and $\beta$-lactoglobulin (results not shown).
None of these proteins had previously been associated with antirotaviral behavior (Kvistgaard et al., 2004).

Conflicting results have been reported on the antirotaviral activity of bovine lactoferrin (Grover et al., 1997; Superti et al., 1997, 2001; Kvistgaard et al., 2004). Lactoferrin eluted in the last part of the gradient of the cation-exchange column, because it was the predominant protein in fraction CM5 (demonstrated immunologically; results not shown). Thus, the present report also suggests that lactoferrin had no effect on rotavirus infectivity in vitro, because the CM5 fraction was unable to inhibit viral replication (Figure 2B).

The results of this study also demonstrate that all the assayed whey protein fractions inhibited, at a final concentration of $0.25 \mathrm{mg} / \mathrm{mL}$, the infectivity in vivo of a viral inoculum of murine rotavirus strain $\mathrm{EMcN}$ containing $10 \mathrm{SD}_{50}$ in the adult mouse model. This inhibition of viral infectivity was confirmed by the absence of serum IgG antibody responses in the challenged animals, except in those mice given the virus incubated with bovine lactadherin. These results demonstrate that although no viral shedding could be detected in stools, these mice became infected.

However, when the animals were challenged with a higher virus inoculum $\left(100 \mathrm{SD}_{50}\right)$, the reduction in viral infectivity induced by the whey proteins was insufficient to protect them against a highly infectious rotavirus strain such as the EMcN strain (McNeal et al., 2004). Only the CM3Q3 fraction induced a strong reduction in the infectivity of the inoculum, and consequently, the viral shedding in stools was delayed by $5 \mathrm{~d}$ compared with the viral shedding of mice in the control groups.

Taken together, the results obtained in vivo showed a variable effect of the tested milk proteins and fractions. The largest impact was seen with the isolated immunoglobulin containing the CM3Q3 fraction, which effectively delayed the shedding of rotavirus in the stools of experimentally infected mice. Interestingly, introduction to the proteolytically active gastric or intestinal milieu did not ruin the effect of CM3Q3. Bovine MUC1 and MMWP demonstrated an intermediate effect, which seems to be reasonable because CM3Q3 is a subfraction of MMWP and MUC1 has been shown to inhibit rotavirus infection very effectively in vitro (Kvistgaard et al., 2004). Although we found that all the assayed milk-derived protein fractions (MMWP, MUC1, lactadherin, and the CM3Q3 fraction) suppressed the shedding of rotavirus antigen in the mice inoculated orally with $10 \mathrm{SD}_{50}$ of EMcN rotavirus (Figure 6A), lactadherin did not protect against the viral infection, as was confirmed by the appearance of rotavirus-specific serum antibodies in those animals given rotavirus treated with this protein (Figure 6B). It is 
feasible that lactadherin could provoke a reduction in the levels of viral antigen shed in feces below the threshold of detection of our ELISA test.

This report demonstrates that commercial whey contains a pool of rotavirus-neutralizing antibodies. To some extent, this was surprising because it had been previously suggested that the inhibitory activity of MMWP is associated with nonimmune components (Kanamaru et al., 1999). Nevertheless, it has been known for decades that bovine milk contains rotaviral antibodies. The highest amount of antibodies is found in colostrum, but antibodies can also be detected later in the lactation period. Heat treatment (pasteurization) has been shown to radically diminish the amount of rotaviral antibodies, and in some cases they became undetectable (Lecce and King, 1982; Yolken et al., 1985). In accordance with these results, preliminary experiments conducted in our laboratory showed that the ability of MMWP to inhibit rotavirus infection was heat labile. Incubating a $10 \mathrm{mg} / \mathrm{mL}$ solution of MMWP in PBS for 10 min at $85^{\circ} \mathrm{C}$ resulted in a change from about 9 to $63 \%$ of Wa infectivity of Caco-2 cells using $0.5 \mathrm{mg}$ of protein $/ \mathrm{mL}$ (results not shown). For hygienic reasons, commercial bovine whey products are heated several times during preparation. It would therefore be crucial for manufacturers to find the ideal heating conditions to maintain as much antirotaviral activity as possible.

The present data are in accordance with a recent study describing the prophylactic effect against rotavirus of a whey protein concentrate (Imucare) in suckling mice (Wolber et al., 2005). Accordingly, it is most likely that a great deal of the effect might be linked to the presence of antirotavirus antibodies in this commercial product as well.

The use of bovine immunoglobulins to obtain passive immunity against rotavirus and other pathogens has been substantially well documented (for a review see Weiner et al., 1999). There has been great interest in the fact that colostrum from the cow contains high amounts of antibodies. To increase the titer against many pathogens, Korhonen et al. (2000) proposed using colostrum from immunized animals, also known as "immune milk." In livestock production the prophylactic effect of products derived from immune milk is well established and there are already commercial products available. However, colostrum is present for only the first few days of the cow's lactation period, making derived products rather expensive. The present findings open the door for the use of MMWP as an attractive alternative.

In summary, bulk bovine milk contains 2 components that hold a major antirotavirus capacity, which are MUC1 and the pool of Ig. In addition, the latter compo- nent may be obtained from comprehensively treated whey products.

\section{ACKNOWLEDGMENTS}

We express our thanks to Arla Foods Innovationcenter Brabrand and Nr. Vium (Denmark) for supplying the milk and milk protein samples. We thank Richard Ward for providing the murine EMcN rotavirus. This work is part of the FØTEK programme supported by the Danish Government and the Danish Dairy Research Foundation.

\section{REFERENCES}

Arias, C. F., P. Isa, C. A. Guerrero, E. Méndez, S. Zárate, T. López, R. Espinosa, P. Romero, and S. López. 2002. Molecular biology of rotavirus cell entry. Arch. Med. Res. 33:356-361.

Benfeldt, C., L. B. Larsen, J. T. Rasmussen, P. A. Andreasen, and T. E. Petersen. 1995. Isolation and characterization of plasminogen and plasmin from bovine milk. Int. Dairy J. 5:577-592.

Burns, J. W., A. A. Krishnaney, P. T. Vo, R. V. Rouse, L. Anderson, and H. B. Greenberg. 1995. Analyses of homologous rotavirus infection in the mouse model. Virology 207:143-153.

European Union. 1986. Council Directive 86/609/EEC on the approximation of laws, regulations, and administrative provisions of the Member States regarding the protection of animals used for experimental and other scientific purposes. Off. J. L 358:1-28.

García-Díaz, A., P. López-Andújar, J. Rodríguez Díaz, C. Torres Barceló, J. M. Ribes, and J. Buesa. 2004. Nasal immunization of mice with a rotavirus DNA vaccine that induces protective intestinal IgA antibodies. Vaccine 23:489-498.

Gil, M. T., C. O. de Souza, M. Asensi, and J. Buesa. 2000. Homotypic protection against rotavirus-induced diarrhea in infant mice breastfed by dams immunized with the recombinant VP8* subunit of the VP4 capsid protein. Viral Immunol. 13:187-200.

Glass, R. I., and U. D. Parashar. 2006. The promise of new rotavirus vaccines. N. Engl. J. Med. 354:75-77.

Grover, M., O. Giouzeppos, R. D. Schnagl, and J. T. May. 1997. Effect of human milk prostaglandins and lactoferrin on respiratory syncytial virus and rotavirus. Acta Paediatr. 86:315-316.

Guerrero, C. A., E. Méndez, S. Zárate, P. Isa, S. López, and C. F. Arias. 2000. Integrin $\alpha(\mathrm{v}) \beta 3$ mediates rotavirus cell entry. Proc. Natl. Acad. Sci. USA 97:14644-14649.

Hvarregaard, J., M. H. Andersen, L. Berglund, J. T. Rasmussen, and T. E. Petersen. 1996. Characterization of glycoprotein PAS-6/7 from membranes of bovine milk fat globules. Eur. J. Biochem. 240:628-636.

Jiang, B., J. R. Gentsch, and R. I. Glass. 2002. The role of serum antibodies in the protection against rotavirus disease: An overview. Clin. Infect. Dis. 34:1351-1361.

Kanamaru, Y., M. Etoh, X. G. Song, T. Mikogami, H. Hayasawa, T. Ebina, and N. Minamoto. 1999. A high- $M_{\mathrm{r}}$ glycoprotein fraction from cow's milk potent in inhibiting replication of human rotavirus in vitro. Biosci. Biotechnol. Biochem. 63:246-249.

Korhonen, H., P. Marnila, and H. S. Gill. 2000. Bovine milk antibodies for health. Br. J. Nutr. 84:S135-S146.

Kosek, M., C. Bern, and R. L. Guerrant. 2003. The global burden of diarrhoeal disease, as estimated from studies published between 1992 and 2000. Bull. World Health Org. 81:197-204.

Kvistgaard, A. S., L. T. Pallesen, C. F. Arias, S. Lopez, T. E. Petersen, C. W. Heegaard, and J. T. Rasmussen. 2004. Inhibitory effects of human and bovine milk constituents on rotavirus infections. J. Dairy Sci. 87:4088-4096.

Lecce, J. G., and M. W. King. 1982. Rotaviral antibodies in cow's milk. Can. J. Comp. Med. 46:434-436.

McNeal, M. M., J. Belli, M. Basu, A. H.-C. Choi, and R. L. Ward. 2004. Discovery of a new strain of murine rotavirus that is consis- 
tently shed in large quantities after oral inoculation of adult mice. Virology 320:1-11.

Newburg, D. S., J. A. Peterson, G. M. Ruiz-Palacios, D. O. Matson, A. L. Morrow, J. Shults, M. L. Guerrero, P. Chaturvedi, S. O. Newburg, C. D. Scallan, M. R. Taylor, R. L. Ceriani, and L. K. Pickering. 1998. Role of human-milk lactadherin in protection against symptomatic rotavirus infection. Lancet 351:1160-1164.

Pallesen, L. T., M. H. Andersen, R. L. Nielsen, L. Berglund, T. E. Petersen, L. K. Rasmussen, and J. T. Rasmussen. 2001. Purification of MUC1 from bovine milk-fat globules and characterization of a corresponding full-length cDNA clone. J. Dairy Sci. 84:2591-2598.

Parashar, U. D., C. J. Gibson, J. S. Bresse, and R. I. Glass. 2006. Rotavirus and severe childhood diarrhea. Emerg. Infect. Dis. 12:304-306.

Parashar, U. D., E. G. Hummelman, J. S. Bresee, M. A. Miller, and R. I. Glass. 2003. Global illness and deaths caused by rotavirus disease in children. Emerg. Infect. Dis. 9:565-572.

Reed, L. F., and H. Muench. 1938. A simple method of estimating fifty percent endpoints. Am. J. Hyg. 27:493-497.

Schacterle, G. R., and R. L. Pollack. 1973. A simplified method for the quantitative assay of small amounts of protein in biologic material. Anal. Biochem. 51:654-655.
Superti, F., M. G. Ammendolia, P. Valenti, and L. Seganti. 1997. Antirotaviral activity of milk proteins: Lactoferrin prevents rotavirus infection in the enterocyte-like cell line HT-29. Med. Microbiol. Immunol. (Berl.) 186:83-91.

Superti, F., R. Siciliano, B. Rega, F. Giansanti, P. Valenti, and G. Antonini. 2001. Involvement of bovine lactoferrin metal saturation, sialic acid and protein fragments in the inhibition of rotavirus infection. Biochim. Biophys. Acta 1528:107-115.

Ward, R. L., M. M. McNeal, and J. F. Sheridan. 1990. Development of an adult mouse model for studies on protection against rotavirus. J. Virol. 64:5070-5075.

Weiner, C., Q. Pan, M. Hurtig, T. Boren, E. Bostwick, and L. Hammarstrom. 1999. Passive immunity against human pathogens using bovine antibodies. Clin. Exp. Immunol. 116:193-205.

Wolber, F. M., A. M. Broomfield, L. Fray, M. L. Cross, and D. Dey. 2005. Supplemental dietary whey protein concentrate reduces rotavirus-induced disease symptoms in suckling mice. J. Nutr. 135:1470-1474

Yolken, R. H., G. A. Losonsky, S. Vonderfecht, F. Leister, and S. B. Wee. 1985. Antibody to human rotavirus in cow's milk. N. Engl. J. Med. 312:605-610.

Yolken, R. H., J. A. Peterson, S. L. Vonderfecht, E. T. Fouts, K. Midthun, and D. S. Newburg. 1992. Human milk mucin inhibits rotavirus replication and prevents experimental gastroenteritis. J. Clin. Invest. 90:1984-1991. 